\title{
INOVAÇÃO EM SERVIÇOS EDUCACIONAIS: O SEMINÁRIO INTERINSTITUCIONAL DE PESQUISA EM ADMINISTRAÇÃO
}

\author{
INNOVATION IN EDUCATIONAL SERVICES: \\ THE INTER-INSTITUTIONAL SEMINAR \\ IN BUSINESS ADMINISTRATION RESEARCH
}

\section{Recebido em: 12/02/2013 Aprovado em: 25/04/2013 Avaliado pelo sistema double blind review Editora Científica: Manolita Correia Lima}

\section{ELIANA ANDRÉA SEVERO elianasevero2@hotmail.com JULIO CESAR FERRO DE GUIMARÃES CRISTINE HERMANN NODARI ERIC CHARLES HENRI DORION PELAYO MUNHOZ OLEA} UNIVERSIDADE DE CAXIAS DO SUL

\section{RESUMO}

A relevância do estudo sobre a inovação em serviço educacional, exercida pelos Programas de Stricto Sensu em Administração, passa pela apreciação do papel que esse cumpre no conjunto da formação profissional e do cidadão na sociedade. O Seminário Interinstitucional de Pesquisa em Administração (SIPAD) foi idealizado pelos Coordenadores dos Programas de Pós-Graduação Stricto Sensu em Administração das universidades do Rio Grande do Sul. Trata-se de uma experiência inovadora, com objetivo de ampliar a interação de conhecimento entre docentes e discentes no que tange a pesquisa em Administração. Para tanto, esta pesquisa tem como objetivo identificar as contribuições do sipad para a pesquisa em Administração, geradas por meio das sete edições (2006-20I2), bem como analisar a importância dos seminários para os alunos de Mestrado e Doutorado. Os resultados indicam que o sIPAD possibilitou a formação de uma rede de relacionamento no Estado, entre alunos e professores dos Programas Stricto Sensu, possibilitando trocas de informações e desenvolvimento de novos temas de pesquisas em Administração. Os docentes e discentes destacam que houve a troca de informações acerca de técnicas e métodos de pesquisa, além de parcerias para desenvolvimento de novas pesquisas.

Palavras-chaves: inovação em serviços educacionais; seminário interinstitucional; Strictu Sensu.

ABSTRACT

The relevance of the study of innovation in educational services employed by graduate Business Administration degree programs comes from the appreciation of the role it plays in training citizens in our society. The Inter-institutional Seminar in Management Research (ISMR), an initiative that originated at the University of Caxias do Sul, was jointly designed by the Coordinators of Business Administration Graduate Programs at Rio Grande do Sul's universities. It represents an innovative experience that aims to expand the interaction of knowledge between teachers and students with respect to business administration research. This paper therefore aims to identify the ISMR's contributions to business administration research, as generated over seven editions (2006-2012), as well as to analyze the importance of the seminars for Masters' (MSc) and Doctorate students (PhD). The results indicate that the ISMR allowed the formation of a network within the State of Rio Grande do Sul between students and teachers, enabling an information exchange and the development of new research issues in business administration. Both teachers and students pointed out an exchange of information regarding techniques and research methods and partnerships for the development of new research. Keywords: innovation in educational services; inter-institutional seminar; graduate degree programs. 


\section{INTRODUÇÃO}

A literatura sobre inovação em serviços ressalta que nas últimas décadas o tema vem crescendo intensamente, além de ter sido aprofundada e ampliada na direção de uma abordagem integradora, que reúna bens e serviços (e suas especificidades) sob um mesmo quadro teórico-conceitual de análise (GALLOUJ; WEINSTEIN, I997; SUNDBO; GALLOUJ, I998; GALLOUJ, 2007). Atualmente o setor de serviço cresce em larga escala, recebendo importância no produto interno das nações, tanto em países desenvolvidos quanto em países em desenvolvimento. Entre os serviços em crescimento estão os serviços educacionais.

Segundo Michael (2004) nunca se buscou tanta educação como neste início de século. Para o indivíduo, o conhecimento tornou-se ferramenta necessária para o sucesso profissional e pessoal (PALÁCIO; MENESES; PÉREZ, 2002). Para Meyer Jr. e Murphy (2003) o ensino superior cresce como resultado do aumento da necessidade de profissionais qualificados, da busca por maior qualidade de ensino, do crescimento do acesso ao ensino superior, das pressões governamentais e da necessidade de prestar contas a sociedade pelo uso de recursos públicos e privados escassos.

A inovação em ensino superior pode incidir em diversos sentidos. Segundo Findlow (2008) pode apresentar-se de formas variadas: o desenvolvimento de pesquisas dentro das universidades; mudanças nos tradicionais métodos de ensino; o uso de novas Tecnologias de Informação e Comunicação (TIC) para o ensino; e a oferta de novos cursos de ensino superior que atendam as necessidades específicas de conhecimentos da atualidade.

A relevância do estudo sobre a inovação em serviço educacional, exercida pelos Programas de Stricto Sensu em Administração, passa pela apreciação do papel que esse cumpre no conjunto da formação profissional e do cidadão na sociedade. A inovação no ensino, assim como no setor de serviços, ocorre principalmente na melhoria e incremento de elementos que compõem os processos, que neste caso compreendem o ensino-aprendizagem, o qual ocorre em espaços pedagógicos como a sala de aula, projetos de extensão, 
desenvolvimentos de artefatos e artigos científicos, e projetos de dissertação e teses em administração.

O Seminário Interinstitucional de Pesquisa em Administração (SIPAD) foi idealizado pelos Coordenadores dos Programas de Pós-Graduação Stricto Sensu em Administração das universidades do Rio Grande do Sul (RS). Trata-se de uma experiência inovadora, com objetivo de efetivar um evento itinerante a fim de ampliar a interação de conhecimento entre docentes e discentes no que tange a pesquisa em Administração. O evento é destinado exclusivamente para apresentação dos projetos de dissertação e tese dos alunos dos Programas de Stricto Sensu em Administração. Neste contexto, houve a interação entre as cinco universidades no Rio Grande do Sul que mantêm os cursos de Mestrado e Doutorado em Administração, ou seja, Pontifícia Universidade Católica do Rio Grande do Sul (PUCRs), Universidade do Vale do Rio dos Sinos (unisinos), Universidade Federal do Rio Grande do Sul (UfRGS), Universidade Federal de Santa Maria (UfSM) e a Universidade de Caxias do Sul (ucs).

Por iniciativa do Programa de Pós-Graduação Stricto Sensu em Administração da Universidade de Caxias do Sul (PPGA/UCs), ocorreu em 2006 O I SIPAD, sendo que este ainda estava preso aos paradigmas de um evento tradicional. Foi pensado inicialmente como um evento com um rol de palestrantes nacionais e internacionais e com inscrições de artigos e sua respectiva apresentação, ou seja, da mesma forma como a maioria dos eventos atuais. Entretanto, em determinado momento se percebeu que o evento poderia ser diferente. Coerentemente, houve uma interação entre coordenadores dos PPGAS do Rio Grande do Sul, tornando-se possível realizar um evento voltado à troca de ideias, aperfeiçoamento de relações, busca de uma integração da pesquisa, enfim, um evento inovador.

O SIPAD acontece anualmente alternando a sede entre as Instituições de Ensino Superior (IEs) dos Programas de Pós-Graduação Stricto Sensu em Administração das universidades do Rio Grande do Sul, e tem como objetivo promover o intercâmbio de conhecimento e das práticas de pesquisa em administração, discutindo acerca da importância de incentivar a pesquisa nos diversos campos da administração, entre eles: empreendedorismo, inovação, 
estratégia, gestão da produção, competitividade, inserção internacional, liderança nas organizações, marketing, gestão da mudança, processo de aprendizagem, inteligência empresarial, pesquisa e desenvolvimento, economia, desenvolvimento sustentável, entre outros.

Destaca-se que o SIPAD também pode ser um espaço para incentivar graduandos e graduados em Administração a seguir no processo da educação continuada, pois nas apresentações de projetos de dissertação e tese é possível instigar a pesquisa, assim como estes projetos mostram os caminhos e lacunas na produção científica dos cursos de Pós-Graduação Stricto Sensu em Administração.

Tendo em vista tal contexto, esta pesquisa tem como objetivo identificar as contribuições do SIPAD para a pesquisa em Administração, geradas por meio das sete edições (2006-20I2), bem como analisar a importância dos seminários para os alunos de mestrado e doutorado, por meio da percepção de discentes e docentes do PPGA/Ucs. Neste sentido, as questões de pesquisa são traduzidas por: i) qual é a importância do SIPAD para a pesquisa em Administração; ii) quais as técnicas de pesquisa e as áreas da administração com maior difusão do conhecimento? Além desta seção introdutória, este artigo está organizado nas seguintes seções: revisão teórica dos temas inerentes à inovação em serviços educacionais; à pesquisa em Administração; metodologia empregada; resultados e discussões e considerações finais. 
REFERENCIAL TEÓRICO

\section{INOVAÇÃO EM SERVIÇOS EDUCACIONAIS}

Os estudos sobre inovação abarcam a produção e disseminação do conhecimento, que é produzido em decorrência de problemas e oportunidades de mercado, demandando a integração das diversas áreas do conhecimento. Neste contexto, é inegável o estreito vínculo entre a Educação Superior, mais especificamente entre o Programa Stricto Sensu em Administração, a pesquisa, a produção do conhecimento e a inovação.

Para Nóvoa (1995), durante muitos anos a inovação em serviços educacionais e em ensino ficou oscilando entre o nível macro do sistema educativo e o nível micro da sala de aula. Nesse período, criar inovação era conceber e implementar reformas estruturais do sistema educativo (nível macro). A inovação em serviços educacionais está associada às práticas de ensino-aprendizagem que alterem, de algum modo, o sistema unidirecional de relações que caracterizam o ensino tradicional (LUCARELLI, 2000). Entretanto ainda são poucas as experiências inovadoras nas IES, contudo, existem muitas intenções de mudança.

Atualmente, as inovações em serviços educacionais e em ensino podem ser implantadas e desenvolvidas em nível micro no contexto dos Programas de Stricto Sensu em Administração. Neste sentido, abarca criar condições organizacionais para que a inovação aconteça, para que os docentes e discentes se sintam motivados em desenvolver inovações nos métodos de ensino e serviços educacionais, e gratificados em participar das inovações, destacando-se todos como parte responsável pela inovação.

Carbonell (2002) aponta alguns fatores básicos que promovem a inovação no ensino, sendo eles: i) equipes docentes sólidas e comunidade educativa receptiva; ii) rede de cooperação e intercâmbio, assessores críticos e outros apoios externos; iii) proposta da inovação e a mudança dentro de um contexto cultural; iv) ambiente de confiança e bem-estar, comunicação intensa nas relações interpessoais; v) institucionalização da inovação; vi) criação de oportunidades para que as inovações possam ser vividas 
com intensidade, refletidas em profundidade e avaliadas com exatidão. Consoante isso, as IEs precisam entender e absorver o processo de inovação para poder exercitá-lo e estimulá-lo no dia-a-dia dos discentes e dos docentes (CARVALHO, 1998).

Uma inovação nos serviços educacionais parte das necessidades internas do quadro docente e discente, não advém de mandatos administrativos ou institucionais, corroborando com a visão Neoschumpeteriana em que o empreendedor não é a única mola propulsora de inovação (HERNÁNDEZ et al., 2000). A inovação no ensino é concebida à medida que se busca respostas à preocupação proveniente de uma prática que não satisfaz às expectativas dos docentes e dos discentes do meio acadêmico.

De acordo com Silva (20I0) e Mota (20II), a IEs dispõe do parque de equipamentos e congrega a gama de competências necessárias que podem promover condições de possibilidade para o desenvolvimento científico, o progresso econômico, a justiça social, a sustentabilidade, a preservação do ambiente e a inovação. Ou seja, a universidade, os Programas de Stricto Sensu, podem construir ambientes que favoreçam o desenvolvimento da cultura da criação e inovação.

O SIPAD é caracterizado como uma inovação nos serviços educacionais, os Programas de Pós-Graduação Stricto Sensu em Administração das universidades do RS o desenvolveram para ampliar o conhecimento no que tange a pesquisa em Administração. O evento visa discutir as práticas de pesquisa, com intuito de fomentar o conhecimento nas diversas áreas temáticas da Administração, bem como dos métodos e técnicas de pesquisa para a construção das dissertações e teses em Administração.

\section{A PESQUISA EM ADMINISTRAÇÃO}

A pesquisa em Administração de empresas no Brasil tem crescido quantitativamente nos últimos anos. Entretanto, questiona-se que a qualidade não tem acompanhado a quantidade. Este tema tem sido objeto de interesse e preocupação de pesquisadores na área de Administração (BERTERO; KEINERT, I994; VERGARA; CARVALHO JR., I995; HOPPEN, I998). Estes 
autores enfatizam que nossa produção é periférica, metodologicamente deficiente, epistemologicamente falha, sem originalidade e pratica, em grande escala, mimetismo mal informado.

No Brasil, diversas autocríticas sobre a produção do conhecimento científico em Administração têm sido veiculadas nos Encontro da Associação Nacional de Pós-Graduação e Pesquisa em Administração (ENANPAD). Roesch (2003) ressalta que a ciência brasileira na área da Administração não avança porque importa modelos teóricos, temas de pesquisa e metodologias, que as pesquisas desenvolvidas são insuficientemente delineadas, metodologicamente confusas, e com pouco manuseio de dados empíricos.

Atualmente as IEs buscam novas estratégias e alternativas pedagógicas capazes de suprir as demandas provenientes do turbulento mercado. Os modelos de ensino-aprendizagem devem estar em constante evolução a fim de cobrir as expectativas do educando na evolução da prática do ensino em Administração. Num sentido amplo, a expressão estratégias de ensino-aprendizagem inclui termos como métodos, técnicas, meios e procedimentos de ensino e significa a "aplicação dos meios disponíveis com vistas à consecução de seus objetivos” (GIL, I994, p. 63). O contexto do ensino de pesquisa em Administração é igualmente influenciado por estas premissas da dinâmica do ambiente.

Para Naisbitt (1984, p. 65):

Em um mundo que está em constante mudança, não há um assunto ou conjunto de assuntos que lhe serão úteis para o futuro próximo, menos ainda para toda a vida. A mais importante habilidade para adquirir agora é aprender a aprender. Se você sabe como aprender, você será capaz de se adaptar diante de quaisquer mudanças tecnológicas, sociais e econômicas, que venham a ocorrer. Ainda, destaca-se a necessidade de ampliar os horizontes de pesquisa, envolvendo temas e abordagens metodológicas próximas aos problemas vivenciados por discentes e docentes. A educação além de ser responsável pela capacitação do aluno enquanto interveniente de uma cena social, a qual exige habilidades necessárias para resolver problemas organizacionais, deverá estar apta à eficácia do processo ensino aprendizagem e ciente 
da necessidade de capacitação de seus alunos diante das expectativas das organizações. A pesquisa em Administração, por sua vez, está indiscutivelmente associada a estes fatores.

Segundo Cooper e Shindler (2003) o estudo de métodos de pesquisa possibilita habilidades necessárias para resolver problemas e desafios de um ambiente de tomada de decisões. O ambiente de tomada de decisões está cada vez mais complexo e exige que os administradores tenham mais e melhores informações para sustentar e tornar segura suas decisões. Coerentemente, o desenvolvimento do processo de ensino-aprendizagem é convergente com a necessidade de eficácia no ensino da pesquisa em Administração. Para alcance desta eficácia é imprescindível que os pesquisadores tenham consciência da importância da confiabilidade e solidez de suas pesquisas como base para a tomada de decisões das organizações.

Para que uma pesquisa seja sólida e confiável, na qual os administradores possam basear suas decisões de alto risco, requer-se a compreensão do método científico para condução adequada da pesquisa. A exigência do mercado por informações melhores e mais rápidas traz uma perspectiva positiva para os pesquisadores. Os pesquisadores, por sua vez, hão de estar cada vez mais preparados e com domínio da metodologia da pesquisa, com finalidade de tornar a pesquisa confiável, visto que a pesquisa em Administração é uma investigação sistemática que fornece informações para orientar as decisões empresariais (COOPER; SHINDLER, 2003).

A pesquisa em Administração é, portanto, uma ciência empírica, de natureza social. Esta, segundo Hair et al. (2005) está em busca de respostas que reúne, analisa, interpreta e relata informações de modo que as decisões administrativas se tornem mais eficazes. Para Cooper e Schindler (2003) a pesquisa em Administração abrange uma investigação sistemática que fornece informações para orientar as decisões empresarias.

Assim, sendo a Administração uma ciência social, podem-se utilizar diferentes métodos para investigá-la. O método científico "é a alma da teoria [...] inclui as concepções teóricas de abordagem, o conjunto de técnicas que possibilitam a construção da realidade e o sopro divino do potencial criativo do investigador" (MINAYO, 1994, P. I6). 
Marins (1994) explicita a variabilidade do método de pesquisa em Administração, categorizando em métodos convencionais e não convencionais, observa que o método é reflexo das nossas necessidades e possibilidades materiais, ao mesmo tempo em que nelas interfere. Observa que o método científico se transforma no decorrer da História. Não se pretende aqui entrar na particularidade dos métodos científicos e suas aplicações na inferência da realidade, e sim observá-lo enquanto processo dinâmico e adaptável em relação aos objetivos da pesquisa em administração em si. Assim, pode-se refletir sobre o próprio ensino da pesquisa em administração e seus objetivos enquanto função de suprir a necessidade do pesquisador enquanto agente, que capta informações relevantes à prática da administração, às organizações e à própria geração de conhecimento seja pelo discente ou docente.

A pesquisa em Administração é vista de forma isolada pela maioria das IES, havendo poucos exemplos de cooperação. A sistemática de divulgação de suas pesquisas, ainda está presa a modelos tradicionais, com eventos isolados, em formatos que permitem pouca ou nenhuma interação. Neste sentido, percebe-se que uma dinâmica interativa pode oportunizar um maior aprendizado, seja para o iniciante em pesquisa, seja para os pesquisadores que conseguem ver o todo da pesquisa em sua região.

Neste sentido, é fundamental também desenvolver pesquisa local de alta qualidade. Necessita-se desvendar as práticas, apresentar sugestões para resolver problemas sociais e organizacionais e criar teoria local, multiplicando pesquisadores locais hábeis. Está na hora de valorizar o rigor metodológico, a seriedade, a persistência e a disciplina de trabalho como qualidades imprescindíveis do pesquisador (ROESCH, 2003). Coerentemente, é necessário criar uma comunidade de pesquisa atuante, de onde emerja a colaboração entre os pares com ênfase no debate e crítica. 


\section{METODOLOGIA}

\section{TIPO DE ESTUDO, OBJETIVO E TÉCNICAS ADOTADAS}

Este estudo se caracteriza por ser uma pesquisa qualitativa de caráter exploratório (GIL, I994; CRESWELL, 2007), por meio de um estudo de caso (YIN, 2005), com finalidade de contribuir de forma científica, agregando conhecimento à pesquisa em Administração, a qual abrange diversas áreas de estudo. Pretende-se identificar as contribuições do SIPAD, geradas por meio das sete edições (2006-20I2), bem como analisar a importância dos seminários para a pesquisa e para os alunos de Mestrado e Doutorado em Administração, por meio da percepção dos discentes e docentes do PPGA/UCS.

Para Creswell (2007) a pesquisa qualitativa é caracterizada por ser exploratória, pois os pesquisadores exploram um tópico quando suas variáveis e bases teóricas são desconhecidas. A pesquisa exploratória é desenvolvida com o objetivo de proporcionar uma visão geral sobre o assunto que está sendo pesquisado, tendo como principal finalidade desenvolver, esclarecer e modificar conceitos e ideias (gil, 1994). Segundo Yin (2005), o estudo de caso trata-se de uma investigação empírica, que investiga um fenômeno contemporâneo inserido em um contexto.

Com base na revisão da literatura se estabeleceu a base conceitual, para a consolidação do referencial teórico a ser utilizado no desenvolvimento deste estudo. Na sequência, os dados foram coletados para se alcançar o entendimento do problema de pesquisa. Conforme Malhotra et al., (2005) e Lakatos e Marconi (200I) a entrevista em profundidade é a técnica fundamental de coleta de dados na pesquisa qualitativa, pois apresenta o propósito de descobrir questões implícitas, onde o respondente é induzido a comentar sobre suas crenças, atitudes e informações subjacentes ao tema em estudo. Gil (I994) ressalta a entrevista como sendo uma das técnicas de coleta de dados mais utilizada nas ciências sociais. Para tanto, este estudo utilizou a entrevista individual, semiestruturada, em profundidade, com um roteiro básico de questões, sendo a técnica que melhor se adaptou ao contexto metodológico da pesquisa. Foram sujeitos da pesquisa: três 
professores permanentes do PPGA/UCs; dez alunos das Turmas de Mestrado e cinco alunos das Turmas de Doutorado. O tempo médio de cada entrevista foi de aproximadamente 28 minutos.

Conforme Laville e Dionne (1999), por meio da análise de conteúdo procura-se desmontar a estrutura e os elementos do conteúdo, com vistas a esclarecer suas diferentes características e significação. Entretanto, a análise de conteúdo não é um método rígido, ao contrário, ela constitui, antes, um conjunto de vias possíveis nem sempre claramente balizadas, para a revelação do sentido de seu conteúdo (LAVILLE; DIONNE, 1999).

Para análise e interpretação dos dados, o método utilizado se deu de acordo com a Análise de Conteúdo, que conforme Bardin (2004) consiste em elementos que permitem a apreciação das comunicações e fornecem informações suplementares. As categorias utilizadas para análise estão baseadas no referencial teórico e nos objetivos da pesquisa, sendo elas: I) importância do SIPAD; II) práticas de pesquisa; e, III) áreas da administração.

Por fim, verificou-se a categorização final das unidades de análise que foram distribuídas por entre as categorias previstas, para em seguida se realizar uma descrição e, finalmente, a interpretação, quando é possível um emparelhamento dos dados recolhidos com a revisão teórica realizada, com a finalidade de compreendê-los em profundidade.

\section{ESTUDO DE CASO}

O PPGA/UCs iniciou suas atividades em 2006 com a implantação do Mestrado Acadêmico em Administração, tendo como linhas de pesquisa: I) estratégia e gestão da produção; e, II) gestão da inovação e competitividade. Neste sentido, PPGA/UCS visa estabelecer equilíbrio entre o mundo acadêmico e o mundo empresarial, com a missão institucional de produzir, sistematizar e tornar o conhecimento acessível à sociedade. Seu corpo docente reúne docentes titulados em instituições de renome internacional, imprimindo ao Programa um caráter internacional, bem como a aproximação dos discentes aos conhecimentos gerados em diversas partes do mundo, dando-lhes a oportunidade de acompanhar a evolução do conhecimento e da pesquisa nas áreas do PPGA/UCS. 
Em 20Io, em decorrência das ações realizadas no âmbito do ensino e da pesquisa em Pós-Graduação em Administração, implantou-se o Doutorado em Administração, tendo com foco a linha de pesquisa de gestão da inovação, competitividade e mercado, oferecido em associação pelos Programas de Pós-Graduação em Administração da Pontifícia Universidade Católica do Rio Grande do Sul (PPGAD/PUCRS) e da Universidade de Caxias do Sul (PPGA/ UCS).

Atualmente o PPGA/UCs conta com doze professores permanentes, dois professores colaboradores e quatro professores visitantes. Por se tratar ainda de um programa novo, em 2008 teve-se a primeira turma de formandos de Mestrado. Consoante isso, conta com sete turmas de Mestrado e três turmas de Doutorado.

O PPGA/UCs incentiva convergência entre dois perfis de competência. Primeiro, gerando intervenientes de elevado nível que agirão como gestores ou experts especializados na identificação e a implantação de soluções aos problemas organizacionais complexos. Segundo, formando professores pesquisadores capacitados para desenvolver uma visão realista e pragmática da gestão de empresas bem como para utilizar uma abordagem rigorosa na análise dos problemas organizacionais.

Neste contexto, o PPGA/UCs além de ser Acadêmico é também caracterizado pela grande importância atribuída à aplicação dos conhecimentos, à resolução dos problemas organizacionais e à tomada de decisões, centrado nas repercussões práticas da investigação e respondido eficazmente às necessidades atuais da sociedade. 


\section{RESULTADOS E DISCUSSÕES}

A seguir, apresenta-se a estrutura final de categorias temáticas utilizadas na análise das falas dos entrevistados, assim como os resultados, bem como alguns trechos ilustrativos das entrevistas. Os mestrandos estão identificados com a letra $\mathrm{M}$ seguidos do número (I, 2, 3, 4, 5, 6, 7, 8, 9 e Iо). Os doutorandos estão identificados com a letra $\mathrm{D}$ seguidos pelos respectivos números (I, 2, 3, 4 e 5). Já os professores estão identificados por PI, P2 e P3.

\section{PERCEPÇÕES DOS DOCENTES SOBRE O SIPAD}

\section{Importância do SIPAD para a Pesquisa em Administração}

Na visão dos docentes, o SIPAD caracteriza-se como um ambiente propício para a troca de conhecimentos no que tange a pesquisa em Administração, assim como das temáticas dos projetos de dissertação e tese, criando um espaço de discussão e troca de experiências acadêmicas entre alunos e professores de Programas de Pós-graduação em Administração.

O entrevistado PI ressalta que o sipad é uma ideia inovadora, referente aos Programas Stricto Sensu no Brasil, tornando-se um evento que fomenta a pesquisa, visando resolver problemas e desafios em um ambiente de tomada de decisões, contribuindo para a formação e desenvolvimento discente e docente, o que Marins (1994) e Cooper e Shindler (2003) consideram fundamental para a pesquisa em administração, pois fornece informações para orientar as decisões empresariais.

(PI) "foi um marco, a partir da ideia que nasceu aqui no PPGA/Ucs inédito no Brasil, referente aos Stricto Sensu do Rs" (...). (P2) "O evento fomentou a possibilidade dos alunos trocarem informações, receberem críticas construtivas de seus projetos pelos demais professores dos outros Programas Stricto Sensu, houve troca de experiências entre os pesquisadores e alunos das várias Instituições" (...). (P3) "se trata de um evento muito interessante, em que os alunos e professores podem trocar conhecimento, interagir no que diz respeito a pesquisa em administração” (...). 


\section{Práticas de Pesquisa mais difundidas}

Os docentes entrevistados destacaram que o sIPAD é um espaço onde há uma intensa disseminação de práticas de pesquisa em administração, pois ocorre a divulgação de métodos e técnicas de pesquisa empregadas pelos discentes nos projetos de dissertação e tese. Outra forma de divulgação das práticas de pesquisa ocorre por meio dos minicursos e palestras ministradas pelos docentes, as quais apresentam diferentes métodos para a investigação na área de ciências sociais (MINAYO, I994; HAIR et al., 2005). Conforme o entrevistado Pı houve também a formação de uma rede de relacionamentos no estado, entre alunos e professores dos Stricto Sensu, possibilitando trocas de informações e o desenvolvimento de novas pesquisas na área de Administração.

(PI) "visualizei um intercâmbio crescente de participação de cada aluno nas apresentações (...) as técnicas de pesquisa são apresentadas pelos alunos e discutidas pelos professores" (...) houve formação de uma rede de relacionamentos no estado, entre alunos e professores dos Stricto Sensu, além de muitos contatos pessoais possibilitando trocas de informações e desenvolvimento de novas pesquisas (...). (Р3) "por se tratar de um encontro entre diversas universidades acontece a troca de métodos e práticas de pesquisa mais propicias e utilizadas em cada universidade, conforme a formação e interesse dos pesquisadores das diferentes universidades” (...). (P2) "Cada instituição tentou incrementar atividades dentro do evento, minicursos, práticas de pesquisa, método tanto informal como formal, palestras com convidados internacionais, palestras com representantes da CAPES, acho isso muito válido” (...).

Entretanto, o entrevistado PI destaca que nas primeiras edições do evento, em alguns momentos, houve divergências em relação à visão e gestão do evento entre os coordenadores das IES federais e das IES particulares. Tudo indica que foi por se tratar de um evento inovador, que tinha como pressuposto ampliar a interação de conhecimento entre docentes e discentes com relação à pesquisa em Administração. 
(PI) "creio que as lideranças dos Programas em determinado momento não perceberam que o evento deveria ser focado para os alunos (...) houve divergências em relação à visão e gestão do evento entre os Coordenadores das Instituições Federais e das Instituições Particulares" (p2).

No que tange a qualidade metodológica da pesquisa em Administração, os docentes perceberam que os projetos de dissertação muitas vezes apresentavam métodos e técnicas de pesquisas confusas e mal interpretadas. Os entrevistados ressaltam que há falta de reflexão dos discentes, em parte porque faltou revisão metodológica, bem como a crítica de escolha de tais técnicas de pesquisa, por parte dos orientadores.

Já nos projetos de tese é verificada a qualidade metodológica, pois os discentes muitas vezes são qualificados e atuam como docentes nos cursos de Administração, bem como ministram disciplinas de metodologia da pesquisa e atuam como orientadores de Trabalho de Conclusão de Curso (TCC). Consoante isso percebe-se que com o avanço do conhecimento, emerge a qualidade da pesquisa, a utilização de métodos e técnicas adequadas, o potencial da pesquisa qualitativa, algo notável em pesquisas desenvolvidas por meio de estudos de caso, e o manuseio de dados empíricos. Esses elementos primam para o desempenho da produção de dissertações e teses em Administração no Brasil. Vale destacar que a produção científica em Administração também sai fortalecida, o que Roesch (2003) considera insuficientemente delineada, metodologicamente confusa, e com pouco manuseio de dados empíricos.

\section{Áreas da Administração com maior difusão do conhecimento}

Para os docentes, diversas áreas da Administração são abarcadas, em virtude das diferentes temáticas dos projetos desenvolvidos, sendo que estes estão alinhados com as linhas de pesquisa dos Programas de Stricto Sensu. Neste contexto, a área de inovação ( $\mathrm{P}_{1}, \mathrm{P}_{2}$ e $\mathrm{P}_{3}$ ); metodologia e técnicas de pesquisa ( $\mathrm{P}_{\mathrm{I}}$ e $\mathrm{P}_{3}$ ); e, empreendedorismo ( $\mathrm{P}_{2}$ ); foram as mais lembradas pelos entrevistados. 


\section{PERCEPÇÕES DOS DISCENTES DE MESTRADO SOBRE O SIPAD}

\section{Importância do SIPAD para a Pesquisa em Administração}

A percepção dos mestrandos acerca da importância do SIPAD abrange a divulgação de projetos de pesquisa que abarcam diferentes temáticas de estudo. Consoante isso os discentes visualizam os itens necessários, e as técnicas adequadas para a estruturação de um projeto de dissertação (LAVIllLe; DiOnNe, I999; LaKatos; Marconi, 200I). Destaca-se também o fato de haver uma interação entre os discentes e docentes das diversas IES, contribuindo para a pesquisa, para a troca de conhecimentos, de experiências, de referências bibliográficas e até de parcerias para desenvolvimento de artigos.

(MI) "divulgar e integrar os cursos e os projetos" (...). (M3) "justificar e fundamentar a importância do desenvolvimento da pesquisa e da socialização desta no meio acadêmico e a com a sociedade" (...). (M4) "visibilidade, reforço de marca institucional e inserção do programa entre as principais universidades gaúchas" (...). (M5) "constrói relações de pesquisa e de trocas com as outras universidades" (...). (M2) "intercâmbio de ideias entre as diferentes instituições, para o aluno, porque tem a oportunidade de discutir ideias e obter sugestões de professores, para a universidade participante, porque expõe os seus alunos” (...). (M6) integração entre os programas troca de informações, formação de parcerias, acréscimo para os projetos dos alunos (...). (M7) "conhecer o que está sendo pesquisado por professores e alunos de outras instituições" (...). (M4) "ao ver as sessões de apresentação dos projetos coletei informações importantes, principalmente sobre metodologia" (...). (Mro) "você consegue ver como é organizado as ideias de um projeto, quais os itens que são importantes" (...). (M8) "troca de experiências entre os pesquisadores" (...). (M9) "troca de conhecimento e experiências entre os participantes, maior interação entre professores e/ou alunos” (...). (M4) "com certeza houve intercâmbio de conhecimento e de práticas de pesquisa, principalmente no que tange a metodologia a ser aplicada nos projetos de dissertação e nos artigos desenvolvidos pelos alunos” (...). 


\section{Práticas de pesquisa mais difundidas}

Os mestrandos destacaram que o sipad é um evento onde se visualiza diferentes práticas de pesquisa em Administração. O evento fomenta e esclarece dúvidas acerca dos métodos e técnicas de pesquisa, além de aproximar os pesquisadores de diferentes Programas. Os entrevistados também ressaltaram a possibilidade de conhecimento referente aos temas estudados em Administração, o que permite a avaliação do projeto de dissertação sob outras perspectivas.

Coerentemente, o SIPAD emerge como interessante oportunidade para selar parcerias entre docentes e discentes dos diversos Programas de Stricto Sensu. O evento trouxe à tona o aprendizado de várias temáticas, ideias para o desenvolvimento de artigos e de novos projetos de dissertação, assim como de pesquisas futuras. Formou-se uma rede de relacionamentos e contatos para trocas de informações e desenvolvimento de novas pesquisas.

Outro ponto importante diz respeito aos minicursos que acontecem em horários distintos às apresentações, que tratam de métodos de pesquisa qualitativa e quantitativa, assim como técnicas para a elaboração de artigos científicos.

(M3) "O SIPAD traz a oportunidade de escrever artigos em conjunto com outros pesquisadores, trazendo pontuação para ambas as instituições" (...). (M5) "eu tive a oportunidade de conhecer e trocar ideias com professores que possuem conhecimento na minha área de investigação e esclarecer alguns pontos que ainda não estavam muito bem delimitados em minha pesquisa" (...). (M7) "ao ver as sessões de apresentação dos projetos coletei informações importantes, principalmente sobre metodologia" (...). (M9) "achei os minicursos muito interessantes, pois consegui esclarecer algumas dúvidas que tinha sobre determinadas técnicas de pesquisa quantitativa” (...).

Os mestrandos destacaram a importância do rigor metodológico, apontado pelos docentes nas bancas de apresentação dos projetos, uma vez que houve espaços de reflexão e apreciação teórica dos métodos e técnicas de pesquisa em Administração. Muitos discentes acabaram alterando e/ou modificando a metodologia utilizada no projeto de dissertação. 


\section{Áreas da Administração com maior difusão do conhecimento}

Para os mestrandos, a área com maior difusão do conhecimento foi a Metodologia da pesquisa, sendo citada por todos os entrevistados. A segunda área mais citada foi a de inovação, apontada por seis mestrandos (Mr, M3, M4, M6, M7 e Mio). A área de marketing foi indicada por 3 entrevistados (M2, M3 e M7), assim como as área de estratégias (Mi, M5 e M8) e empreendedorismo (M5, M4 e M9).

\section{PERCEPÇÕES DOS DISCENTES DE DOUTORADO SOBRE O SIPAD}

\section{Importância do SIPAD para a pesquisa em administração}

Os doutorandos relataram que o SIPAD promoveu o intercâmbio de conhecimento entre pesquisadores, docentes, discentes, gestores e colaboradores de organizações públicas e privadas do Rio Grande do Sul. O conhecimento científico necessita ser difundido para a ampliação das fronteiras da ciência. Consoante isso, o SIPAD emerge como um evento inovador, que visa a troca de conhecimento no que se refere à pesquisa em Administração, o que Gallouj e Weinstein (1997) consideram uma inovação em serviços, reforçando a evidência do crescimento do tema na literatura, além do aprofundamento e a ampliação na construção de uma abordagem integradora que reúna os conceitos de inovação de serviços.

(DI) "além do intercâmbio de conhecimento, considero inovadora a possibilidade do aluno apresentar o seu projeto de tese e receber contribuições de professores advindos de outras universidades (...) destaco ainda que evento, sobretudo, reúne pesquisadores exclusivamente da área de administração, o que amplia e aprofunda as contribuições aos nosso projetos de tese de doutorado" (...) (D2) "um aspecto importante neste evento é o network, pois os alunos estabelecem relacionamentos com outros doutorandos, que muitas vezes passam por situações similares, mas que encontram soluções diferentes. Outro network importante pode ser estabelecido com professores de outros programas, os quais são especialistas em determinadas áreas da administração” (...). 


\section{Práticas de pesquisa mais difundidas}

Para os doutorandos, o SIPAD estimulou o debate sobre a importância e os desafios da pesquisa, assim como da formação do docente. Neste sentido, fortalece os Programas de Stricto Sensu em Administração do Rio Grande do Sul, pois muitos discentes atuam como professores e/ou gestores nas organizações.

Conforme ressaltam os doutorandos, a atividade de pesquisa pressupõe a busca de um conhecimento organizado. Coerentemente, há necessidade da utilização de diferentes elementos para facilitar a execução da pesquisa, desde a determinação da metodologia adequada até a divulgação dos resultados, refletindo diretamente na elaboração dos artigos científicos e teses.

(DI) "instigou o debate sobre pesquisa, quais os desafios, quais as oportunidades, ocasionando benefícios para os programas (...) os alunos tornam-se mais questionadores quanto à utilização de métodos e técnicas de pesquisa, isso também reflete na elaboração dos artigos científicos" (...). (D3) "a pesquisa necessita de métodos organizados, no SIPAD foram vistas diferentes práticas de pesquisa, tudo depende do objetivo da pesquisa" (...). (D4) "foram apresentadas e discutidas diversas práticas de pesquisa, isso esclarece os alunos, pois muitos ainda não estão familiarizados com as técnicas (...) outro ponto que achei muito importante foram as palestras e mini cursos que aconteceram durante o seminário, as temáticas de pesquisa qualitativa e quantitativa foram muito interessante, muitas vezes acabamos fazendo confusão entre as técnicas (...) muitos alunos também já estão atuando como professores, neste sentido o ensino sai também fortalecido” (...).

\section{Áreas da Administração com maior difusão do conhecimento}

Para os doutorandos, diversas áreas da Administração tiveram difusão do conhecimento. A inovação foi uma das áreas que apresentou o maior número de projetos, este fato pode estar relacionado às linhas de pesquisa dos programas das intuições de ensino (DI, D2, D3 E D4). Outro fator que tem contribuído para o aprofundamento nos estudos dos processos e antecedentes de inovação é a crescente demanda das empresas, como busca 
de um diferencial competitivo. Percebe-se que a área de marketing também vem sendo difundida, em especial o marketing de relacionamento (D3 E D5), pois aborda os aspectos relacionais entre clientes e fornecedores, surgindo o interesse das relações business to business.

A metodologia da pesquisa tem sido um tema recorrente nas discussões dos projetos de tese e minicursos (DI, D2, D4 E D5), pois é um instrumento fundamental para a robustez dos resultados das pesquisas em Administração. Entretanto, alguns pesquisadores, em geral discentes, dominam certas técnicas de pesquisa e por conta disso são influenciados na escolha destes instrumentos, deixando de avaliar outras possibilidades de métodos de pesquisa. 


\section{CONSIDERAÇÕES FINAIS}

A realização deste estudo demonstrou que o sıpad idealizado pelos Coordenadores dos Programas de Pós-Graduação Stricto Sensu em Administração das universidades do Rio Grande do Sul, trata-se de uma inovação de serviços educacionais, pois além de ser um evento inovador, no que diz respeito às suas características, oportunizou uma significativa experiência de aprendizagem para os discentes e docentes. Assim pode-se afirmar que esta inovação de serviços educacionais confirma as pesquisas de Gallouj (2007) e Gallouj e Weinstein (1997), pois trata-se de uma alteração, para melhoria de característica do produto (pesquisa), sem alterar o sistema.

Já se percebe a formação de uma rede de relacionamento no Estado, entre alunos e professores dos Programas Stricto Sensu, além de contatos pessoais possibilitando trocas de informações e desenvolvimento de novas pesquisas em Administração, corroborando as assertivas de Michael (2004), Findlow (2008), Silva (2010) e Mota (20II), pois fomenta o desenvolvimento de pesquisas dentro e entre as IES.

Ressalta-se que a pesquisa em Administração no estado do Rio Grande do Sul sai fortalecida depois destes seminários. O evento já se encaminha para a oitava edição, sendo possível perceber a formação de grupos de pesquisas interinstitucionais, numa perspectiva de desenvolvimento integrado. Portanto, a necessidade de interagir e dialogar, buscando formar alianças, seja no nível da pesquisa ou de trocas relacionais, é fator positivo para uma região, que estará se fortalecendo cientificamente, formando uma massa crítica capaz de auxiliar na busca constante de resultados, enfrentando a concorrência cada vez mais acirrada em todos os segmentos.

Algumas particularidades foram percebidas no transcorrer desta investigação, principalmente em relação aos alunos entrevistados, que estavam focados nos seus projetos de dissertação, entendendo este como uma pesquisa voltada à solução de problemas e à busca de respostas para questões propostas, por meio da utilização de métodos científicos. No entanto, não se deve esquecer que o evento tem o objetivo principal de promover o intercâmbio de conhecimento e das práticas de pesquisa em 
Administração como um todo. Corroborando com os pressupostos de Roesch (2003), pois o Brasil carece de sugestões para resolver problemas sociais e organizacionais, não impedindo a inserção no circuito científico internacional.

Outro ponto importante refere-se à necessidade de quebrar alguns paradigmas, principalmente na perspectiva se criar uma rede de relacionamento consolidada, com projetos de pesquisas integrados, troca de conhecimento, intercâmbio de docentes e discentes entre os Programas. Coerentemente, o pensamento voltado para a consolidação da pesquisa no Rio Grande do Sul, independente da IES que esteja alocado.

Novas metodologias no ensino da pesquisa em Administração são requeridas com base nas mudanças ocorridas no mercado, desde mudanças tecnológicas, sociais, políticas e comportamentais. O SIPAD representa, segundo este ponto de vista, um processo de aprendizagem moderno, capaz de disponibilizar informações com velocidade e eficiência, permitindo uma coesão entre os participantes, fruto da proximidade, facilitando o desenvolvimento de projetos conjuntos.

Como sugestão de pesquisas futuras, o sIPAD é uma proposta que pode ser desenvolvida em outros Programas de Stricto Sensu do Brasil, permitindo que o intercâmbio científico ocorra por meio de assuntos estudados por mestrandos e doutorandos em Administração. Trata-se de uma forma ousada de aplicar os conhecimentos que esses alunos receberam em sala de aula, não apenas no ambiente gerencial, mas também na sua forma acadêmica, imprimindo um ritmo dinâmico e arrojado na análise teórica com vistas a uma contribuição efetiva na construção de conhecimento. 


\section{REFERÊNCIAS}

BARDIN, L. Análise de conteúdo. 3. ed. Lisboa: Edições 70, 2004.

BERTERO, C. O.; KEINERT, T. M. M. A evolução da análise organizacional no Brasil. Revista de Administração de Empresas, v. 34, n. 3, p. 81-90, 1994.

CARBONELL, J. A aventura de inovar: a mudança na escola. Porto Alegre: Artmed, 2002.

CARVALHO, H. G. Tecnologia, inovação e educação: chaves para a competitividade. Porto Alegre: Artmed, 1998.

COOPER, D. R.; SCHINDLER, P. S. Métodos de pesquisa em administração. 7.ed. Porto Alegre: Bookman, 2003.

CRESWELL, J. W. Projeto de pesquisa: métodos qualitativo, quantitativo e misto. 2.ed. Porto Alegre: Artmed, 2007.

FINDLOW, S. Accountability and innovation in higher education: a disabling tension? Studies in Higher Education, v. 33, n. 3, p. 313-329, 2008.

GALLOUJ, F. Economia da inovação: um balanço dos debates recentes. In: BERNARDES, R.; ANDREASSI, T. (Orgs.). Inovação em serviços intensivos em conhecimento, p. 3-28. São Paulo: Saraiva, 2007.

GALLOUJ, F.; WEINSTEIN, O. Innovation in services. Research Policy, v. 26, n.4-5, p. 537-556, 1997.

GIL, A. C. Metodologia do ensino superior. São Paulo: Atlas, 1994.

HAIR Jr., J.F.; BABIN, B.; MONEY, A. H.; SAMOUEL, P. Fundamentos de métodos de pesquisa em administração. Porto Alegre: Bookman, 2005.

HERNÁNDEZ. F.; SANCHO, J. M.; CARBONELL, J.; TORT, A.; SIMÓ, N.; CORTÉS, E. S. Aprendendo com inovação nas escolas. Porto Alegre: Arte Médicas Sul, 2000.

HOPPEN, N. Sistemas de informação no Brasil: uma análise dos artigos científicos dos anos 90. Revista de Administração Contemporânea, v. 2, n. 3, p. 151-177, 1998.

LAKATOS, E. M. MARCONI, M. A. Metodologia do trabalho científico: procedimentos básicos, pesquisa bibliográfica, projeto e relatório, publicações e trabalhos científicos. 5.ed. São Paulo: Atlas, 2001.

LAVILLE, C.; DIONNE, J. A construção do saber: manual de metodologia em ciências humanas. Porto Alegre: Artmed, 1999.

LUCARELLI, E. Um desafio institucional: inovação e formação pedagógica do docente universitário. In: CASTANHO, S.; CASTANHO. M. O que há de novo na educação superior: do projeto pedagógico à prática transformadora, p. 60-71. Campinas: Papirus, 2000.

MALHOTRA, N. K.; ROCHA, I.; LAUDISIO, M. C.; ALTHEMAN, É.; BORGES, F. M. Introdução à pesquisa de marketing. São Paulo: Prentice Hall, 2005. 
MARINS, G. de A. Metodologias convencionais e não-convencionais e a pesquisa em administração. Caderno de pesquisa em administração. São Paulo, 2\%/Sem. 1994.

MEYER Jr., V.; MURPHY, J. P. Dinossauros, gazelas e tigres: novas abordagens da administração universitária, um diálogo Brasil EUA. 2.ed. Florianópolis: Insular, 2003.

MICHAEL, S. O. In search of universal principles of higher education management and applicability to Moldavian higher education system. The International Journal of Educational Management, v. 18, n. 2, p. 118-137, 2004.

MINAYO, M. C. S. (Org.). Pesquisa social: teoria, método e criatividade. 22.ed.

Petrópolis, RJ: Vozes, 1994.

MOTA, R. O papel da inovação na sociedade e na educação. In: COLOMBO, S. S. (Org). Desafios da gestão universitária contemporânea, p. 81-96. Porto Alegre: Artmed, 2011.

NAISBITT, J. Magatrends. Warner Books, 1984.

NÓVOA, A. As organizações escolares em análise. 2.ed. Lisboa: Publicações Dom Quixote, 1995.

PALACIO, A. B.; MENESES, G. D.; PÉREZ, P. J. P. The configuration of the university image and its relationship with the satisfaction of students. Journal of Educational Administration, v. 40, n. 5, p. 486-505, 2002.

ROESCH, S. M. A. Quem responde pelo desempenho limitado da produção científica em administração no Brasil? Organizações \& Sociedade, v. 10, n. 28, p. 165-168, 2003.

SILVA, E. M. de P. Desenvolvimento tecnológico e inovação: nota sobre Pós-Graduação, Desenvolvimento Tecnológico e Inovação. In: BRASIL. Ministério da Educação.

Coordenação de Aperfeiçoamento de Pessoal de Nível Superior. Plano Nacional de PósGraduação (PNPG 2011-2020). Brasília, DF: CAPES 2010. p. 191-216.

SUNDBO, J.; GALLOUJ, F. Innovation as a loosely coupled system in services. Topical Paper, n. 4, 1998.

VERGARA, S. C.; CARVALHO JR., D. S. Nacionalidade dos autores referenciados na literatura brasileira sobre organizações. Revista Brasileira de Administração Contemporânea, v. 1, n. 6, p. 169-188, 1995.

YIN, R. K. Estudo de caso: planejamento e métodos. 3.ed. Porto Alegre: Bookman, 2005. 


\section{DADOS DOS AUTORES}

\section{ELIANA ANDRÉA SEVERO^ elianasevero2@hotmail.com} Mestre em Administração pela UCS

Instituição de vinculação: Universidade de Caxias do Sul

Caxias do Sul/RS - Brasil

Áreas de interesse em pesquisa: Administração, Inovação e Sustentabilidade Ambiental.

${ }^{\star}$ Rua Francisco Getúlio Vargas, 1130, Bloco F Petrópolis Caxias do Sul/RS 95070-560

JULIO CESAR FERRO DE GUIMARÃES juliocfguimaraes@yahoo.com.br Mestre em Engenharia da Produção pela UFRGS

Instituição de vinculação: Universidade de Caxias do Sul

Caxias do Sul/RS - Brasil

Áreas de interesse em pesquisa: Administração, Inovação e Ensino.

CRISTINE HERMANN NODARI cristine.nodari@gmail.com Mestre em Administração em Administração pela UCS

Instituição de vinculação: Universidade de Caxias do Sul

Caxias do Sul/RS - Brasil

Áreas de interesse em pesquisa: Administração, Inovação e Saúde.

\section{ERIC CHARLES HENRI DORION echdorion@gmail.com}

Doutor em Administração pela Universidade de Sherbrooke - Canadá

Instituição de vinculação: Universidade de Caxias do Sul

Caxias do Sul/RS - Brasil

Áreas de interesse em pesquisa: Administração, Inovação e Empreendedorismo.

PELAYO MUNHOZ, OLEA pelayo.olea@gmail.com

Doutor em Administração pela Universitat Politècnica de Catalunya - Espanha Instituição de vinculação: Universidade de Caxias do Sul

Caxias do Sul/RS - Brasil

Áreas de interesse em pesquisa: Administração e Inovação. 